\title{
Effect of Heat Treatment on Residual Stress of Cold Sprayed Nickel-based Superalloys
}

\author{
Deepika Shrestha ${ }^{1} \cdot$ Fardad Azarmi $^{1} \cdot$ X. W. Tangpong ${ }^{1}$
}

Submitted: 22 July 2021 / in revised form: 10 November 2021/Accepted: 11 November 2021/Published online: 29 November 2021 (C) ASM International 2021

\begin{abstract}
Residual stress formation during cold spraying process may result in deteriorative effects on the performance of coating materials. The objective of this investigation is to characterize residual stress built-up in two wellknown nickel-based superalloys (Inconel 625 and Inconel 718) deposited using cold spraying technique. To this end, the residual stress was precisely measured using x-ray diffraction method. Here, residual stress in the subsurface regions was only studied because the surface properties may alter during sample preparation. The average residual stress was slightly higher in Inconel 625 compared to the Inconel 718 sample. Heat treatment at $800{ }^{\circ} \mathrm{C}$ helped in the reduction of porosities which exerted tensile stress in subsurface regions of both coatings. Stresses with opposite signs could cancel each other and result in reduction of residual stress after heat treatment. However, the recovery of residual stress was higher for Inconel 718 coating. In the next step as-sprayed and heat-treated coating samples were subjected to microindentation test to measure their hardness and study the crack formation in the samples. The assprayed Inconel 625 exhibited higher hardness than Inconel 718 , but the hardness of Inconel 625 decreased more drastically after heat treatment. While the cracks were formed on both as-sprayed samples around indents, no
\end{abstract}

This article is an invited paper selected from presentations at the 2021 International Thermal Spray Conference, ITSC2021, that was held virtually May 25-28, 2021 due to travel restrictions related to the coronavirus (COVID-19) pandemic. It has been expanded from the original presentation.

Fardad Azarmi

fardad.azarmi@ndsu.edu

1 Department of Mechanical Engineering, North Dakota State University, Fargo, ND 58108-6050, USA cracks were found in the heat-treated samples. The results from this study will contribute to better understanding the performance of cold spray deposited superalloys under service conditions and the effect of stress relaxation heat treatment on elimination of residual stress.

Keywords cold spraying $\cdot$ hardness $\cdot$ nickel-based superalloys $\cdot$ residual stress $\cdot$ stress relaxation

\section{Introduction}

Due to its high strength and good mechanical properties, nickel-based superalloys have been widely used in many industrial applications, such as aerospace, automobiles, power generation, nuclear power plants, etc. Among the various nickel-based superalloys, Inconel 718 and Inconel 625 have gained the most attention. Both alloys are designed such that at higher temperatures up to $700{ }^{\circ} \mathrm{C}$, they still show excellent resistance to corrosion, wear, fatigue, with good strength and weldability (Ref 1,2). Inconel 625 has higher molybdenum content than Inconel 718 and offers superior resistance to corrosion under severe service conditions. Inconel 625 is a reasonable candidate for seawater applications, which have a higher risk of pitting and crevice corrosion $(\operatorname{Ref} 3,4)$.

Various additive manufacturing techniques have been developed that give the freedom to design and fabricate geometrically complex components. These advanced technologies allow for the manufacturing of such components in reduced time and with less material consumption compared to traditional manufacturing technologies (Ref 5). These advantages have made thermal spraying and additive manufacturing technologies attractive methods for making medical implants, aircraft components, automobile 
parts, as well as parts and components used in nuclear plants (Ref 6,7). In those technologies, parts and components are deposited or formed layer by layer with good accuracy.

Cold spray (CS), also known as cold gas dynamic spray (CGDS), has gained wide recognition among various industries. In CS, the solid powder as feedstock material is accelerated at a very high velocity through a de-Laval nozzle up to $1200 \mathrm{~ms}-1$. Although, cold spraying is processed in temperatures below the melting points of particles, the quality of deposited coatings can be affected by the instant temperature of the accelerated particles. However, particle size and velocity of in-flight particles are the most critical characteristics which can influence the coating deposition rate and its quality. The accelerated particles impact the substrate of the surface in a solid-state "cold" following intense plastic deformation upon impingement. Due to the solid-state deposition process in CS, it has unique characteristics such as low porosity compared to other conventional thermal spray techniques. In addition, CS has advantages over conventional thermal spray techniques with less unwanted oxidation and phase changes (Ref 8-10). It is believed that residual stress formation during the deposition process in cold spraying is lower than in other thermal spraying techniques due to less steep thermal gradient during spraying and splat formation. Residual stress in the cold spraying process is induced by peening and plastic deformation due to high velocity of solid particles. However, in some CS processes, a thermal mismatch could happen due to the different thermal coefficients of the deposited particles and substrates which could result in formation of extra residual stress (Ref 11).

Residual stress in materials is induced in every manufactured part and every manufacturing process such as machining, casting, forming, etc. Generally, residual stress profile in machining was found tensile at the surface, followed by compressive at the subsurfaces (Ref 12). Chen et al. (Ref 13) studied the thermal effect on the residual stress of broached Inconel 718 and found it followed the stress profile of tensile at the top surface and gradually changed to compressive at the subsurface. After the thermal exposure at $550^{\circ} \mathrm{C}$ for 30 hours, the tensile residual stress dropped to almost zero, and after 3000 hours the residual stress became compressive. Wu and Jiang (Ref 14) studied the effect of thermal relaxation on residual stress and microstructural changes of dual shot-peened Inconel 625 and found the relaxation rate was dependent on annealing time and temperature. Higher compressive residual stress was observed on the top surface of the sample after dual-shot peening which was relaxed after various isothermal temperatures. High compressive residual stress $(-837 \mathrm{MPa})$ was relaxed down to $-487 \mathrm{MPa}$, $-332 \mathrm{MPa}$, and $-178 \mathrm{MPa}$ and was stable at elevated temperatures of 500,600 , and $700{ }^{\circ} \mathrm{C}$, respectively after the first 15 minutes. Lyphout et al. (Ref 15) investigated the residual stress in thick high-velocity oxygen-fuel (HVOF) deposited Inconel 718 coating through various methods. Residual stress of successive tensile and compressive nature along the coating thickness and compressive stress at the interface of coating and substrate were found by different methods. Wang et al. (Ref 16) reported compressive residual stress in as-fabricated Inconel 718 by laser metal powder bed fusion and it was relieved after stress relief heat treatment. After the stress relief heat treatment, the microstructure was homogenized, and the hardness was increased. Kim et al. (Ref 17) found a significant effect of low-temperature range heat treatment on the residual stress of cold sprayed Inconel 718. Low-temperature heat treatment $\left(100-400{ }^{\circ} \mathrm{C}\right)$ resulted in residual stress relaxation, whereas increased temperature resulted in the opposite. The residual stress at low temperature was relieved and at high temperature $400{ }^{\circ} \mathrm{C}$, residual stress was changed to compressive in nature. Singh et al. (Ref 18) reported that the adhesion strength of the cold sprayed Inconel 718 was reduced with the coating thickness that caused the failure in the coating. Residual stress measured at each successive deposition of the coating showed a deceasing trend in the coating build-up direction. However, the coating was delaminated and peeled off from the substrate after the coating thickness reached above approximately $500 \mu \mathrm{m}$ (Ref 18).

Residual stress can be developed in most thermally sprayed coatings due to the momentum of molten particles during impact, and heat transfer during solidification of the splats. Another reason for residual stress built-up in thermally sprayed coatings is due to splat curl-up during solidification and the differences in thermal expansion coefficients between the coating and the substrate. Although the process is called "cold" spraying, high momentum of particles at impact can drastically increase the temperature of the coatings resulting in thermal gradient between substrate and deposition. The difference between temperature of substrate and coating is significantly lower than those formed during thermal spraying processes involving melting of the particles. However, the process still can generate some thermal stresses in the coating material. It has been concluded that plastic deformation during impact followed by flattening of solid particles and thermal stress are dominant factors for residual stress built-up during the cold spraying process (Ref 19, 20). Residual stress formation has been previously studied for Inconel 718 and Inconel 625 deposited by different additive technologies such as selective laser melting (SLM), HVOF, and laser rapid forming (Ref 12-16, 21). The residual stress induced by the CS deposition technique and the effect of heat treatment performed at a range of 
temperature on residual stress was previously studied for some limited materials (Ref 17).

In the present study, residual stresses induced by the CS process in Inconel 625 and Inconel 718 were evaluated by $\mathrm{x}$-ray diffraction. The effects of heat treatment on residual stresses in these two types of coatings were also studied. This work pays attention to the porosity formation and cracks propagation before and after heat treatment using scanning electron microscopy (SEM) and digital microscopy. The results from this study will contribute to better understanding of the performance of CS deposited superalloys under service conditions.

\section{Experimental Procedure}

\section{Materials}

Gas atomized powders of Inconel 718 and Inconel 625, commercially known as PG-AMP-1060 by Plasma Giken (Japan) were used to prepare the sample. The chemical compositions of the Inconel 718 alloy (Ref 22) and Inconel 625 alloy (Ref 23) are given in Table 1.

\section{Cold Spraying Process}

Commercial grade powder PG-AMP-1060 with particle size 45-90 $\mu \mathrm{m}$ was used for CS. PCS1000 high-pressure cold spray system by Plasma Giken (Saitama, Japan) was used for deposition of coating powders. Nitrogen gas was used as the primary gas for the high-velocity stream of compressed gas at $1000{ }^{\circ} \mathrm{C}$. The gas pressure used was $7 \mathrm{MPa}$ and the process parameters are listed in Table 2. Approximately $3 \mathrm{~mm}$ of coating was deposited by cold spraying on aluminum substrates for both Inconel samples in this study. All coating samples were separated from the substrate using Electric Discharge Machining to ensure no extra stress added to the samples during cutting process.

Table 1 Chemical compositions of Inconel 625 and Inconel 718

\begin{tabular}{lll}
\hline Element & Inconel 625 content, wt.\% & Inconel 718 content, wt.\% \\
\hline $\mathrm{Ni}$ & balance & 52.5 \\
$\mathrm{Cr}$ & 22 & 19.0 \\
$\mathrm{Nb}$ & $\ldots$ & 5.2 \\
$\mathrm{Fe}$ & 2 & 18.8 \\
$\mathrm{Al}$ & $\ldots$ & 0.5 \\
$\mathrm{Mo}$ & 9.4 & 3.1 \\
$\mathrm{Ti}$ & $\ldots$ & 0.9 \\
$\mathrm{Nb}+\mathrm{Ta}$ & 4.8 & $\ldots$ \\
\hline
\end{tabular}

Free-standing coating samples were subjected to microstructural characterization and residual stress measurements.

\section{Residual Stress Measurement}

X-ray diffraction method is based on the measurement of changes in crystal lattice spacing in one or several directions with respect to angular shifts of respective diffraction peaks (Ref [24]). Residual stress measurement was performed using an XStress 3000 G2R-F (Stresstech, PA, USA) X-ray diffractometer equipped with a type HPC detector. The parameters and technical features of X-ray diffractometer used for measurement are given in Table 3. The radiation used was $\mathrm{Mn}-\mathrm{K} \alpha$, giving the $2 \theta$ position of $153.5^{\circ}$. The peak position was determined at eighteen different $\Psi$ tilts $(2 \times 0, \pm 15.5, \pm 22.2, \pm 27.6, \pm 32.2, \pm$ 36.7, $\pm 40.9, \pm 45)$. The stress values were obtained by converting the strain using the bulk elastic constant $E=$ $205 G P a$ and $v=0.386$. For the residual stress calculation, $\sin 2 \psi$ method at different tilt angles was used. The residual stress was calculated through the thickness of the sample

Table 2 Process parameters for cold spraying process in this study

\begin{tabular}{ll}
\hline Process parameters & Value \\
\hline Spray Distance, mm & 300 \\
Feed Rate Speed, rpm & 2.4 \\
Current, A & 550 \\
Voltage, V & 33 \\
Pressure, MPa & 7 \\
Primary Gas & Nitrogen \\
Temperature, ${ }^{\circ} \mathrm{C}$ & 1000 \\
\hline
\end{tabular}

Table 3 Process parameters and technical features of x-ray diffractometer for residual stress measurement in this study

\begin{tabular}{ll}
\hline Parameters & \multicolumn{1}{c}{ Condition } \\
\hline Detector Geometry & Modified X \\
Detector Type & HPC, direct detect \\
Tube Power & $30 \mathrm{kV} \mathrm{x} \mathrm{6.6mA,} \mathrm{100 \%}$ \\
Collimator Size (target area size) & $1 \mathrm{~mm} \varnothing$ \\
Radiation & Mn-K $\alpha$ \\
$\lambda$ & $2.10 \AA$ \\
Exposure Time & $10 \mathrm{~seconds}$ \\
Diffraction Plane & 311 \\
Bragg's Angle & 153.5 \\
Penetration Depth & $4.2 \mu \mathrm{m}$ \\
\hline
\end{tabular}


by removal of the material using electrolytic polishing. The residual stress of nickel-based superalloys was measured in longitudinal (spray direction) i.e. $0^{\circ}$, transverse (perpendicular to spray direction) i.e. $90^{\circ}$ and at $45^{\circ}$ as shown in Fig. 1. The residual stress measurement in this study was in compliance with ASTM E915-16.

\section{Microstructural Characterization}

The as-sprayed and heat-treated samples were cut and mounted with epoxy resin. The samples underwent grinding, polishing, and etching according to ASTM E40707(2015) [25]. In order to investigate the microstructural characterization, the cross-section of etched surface was examined using Digital Microscope, VHX-7000 (Keyence Corporation of America, 500 Park Boulevard, Itasca, IL 60143, U.S.A). For the high magnification microstructural characterization, JEOL JSM-6490 LV Scanning Electron Microscopy (JEOL USA, Peabody, MN) was used and the porosity levels of the samples were measured using the image analysis method. Image analysis was performed to determine the apparent porosity content of the coatings from the seven micrographs taken at various locations on each sample according to ASTM E 2109-00.

\section{Micro indentation Test}

Vickers hardness test was performed on all samples using a Micromet 5140, Buhler, USA using an applied load of 100 gf for $15 s$. The micro indentation test was performed for two main reasons. First, measurement of the hardness of all the samples. Second, investigate the crack formation on each sample due to indentation and study the effect of heat treatment on elimination or propagation of the cracks. To this end, it was important to select an appropriate load to induce cracks and also measure the hardness without causing excessive damage to the sample. Eleven indentation tests were performed on each specimen in this study according to ASTM E92-17 (Ref 26). A VHX-7000 digital microscope by Keyence Corporation of America, USA capable of capturing surface profiles was used for observation of indents and cracks induced by the indentation test.

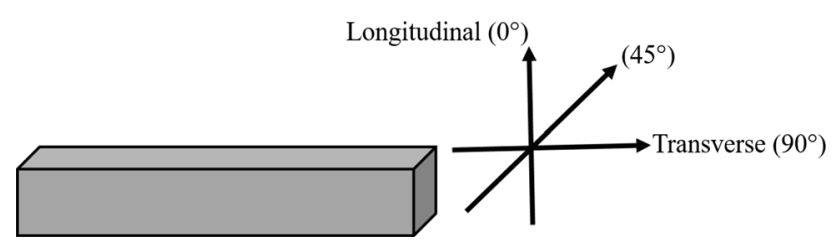

Fig. 1 Schematic diagram showing the directions of residual stress measurement

\section{Heat Treatment Procedure}

Post deposition heat treatments were performed on the assprayed CS deposited coatings to enhance cohesion between the individual lamella by increasing diffusion across splat boundaries, and elimination of internal fine porosity. It is expected that a successful heat treatment operation can also reduce residual stress resulted from the high-velocity impact of the solid particles during the cold spraying process. Both as-sprayed samples were placed in a tubular furnace at $800{ }^{\circ} \mathrm{C}$ for one hour, followed by air cooling. This is the optimum stress relief temperature recommended for nickel-based superalloys (Ref 27).

\section{Results and Discussion}

\section{Microstructural Observation}

Figure 2(a) shows the micrograph of the as-sprayed Inconel 625. The micrograph reveals a relatively dense deposit built-up with a porosity level of $1.67 \pm 0.45$ Area. \% according to image analysis. Pores and cracks with dark contrasts appear in round or elongated shapes as labeled in all micrographs shown in this figure. The cross-section micrograph of the as-sprayed Inconel 718 is shown in Figure 2(b) The porosity level of Inconel 718, 4.39 \pm 0.55 Area. \% is higher than that of Inconel 625 shown in Fig 2(a), and the voids and cracks are mostly in round shapes.

Figure 2(c) and (d) show the cross-sectional micrographs of CS deposited Inconel 625 and Inconel 718 after the stress relief heat treatment at $800^{\circ} \mathrm{C}$. The porosity levels of Inconel 625 and Inconel 718 are measured as $0.95 \pm 0.33$ Area. $\%$ and $2.35 \pm 0.40$ Area. $\%$, respectively. Heat treatment enhances diffusion of atoms that consequently result in elimination of very small pores and an overall reduction of the pore size within the microstructure (Ref 28). In addition, elevated temperature may result in consolidation of inter-particle boundaries that go along with shrinkage of voids. The decreases in porosity contents of these samples are in good agreement with what was reported for heat-treated nickel-based alloys in (Ref 29).

\section{Evaluation of Residual Stress}

Table 4 lists the residual stress distributions on crystallographic planes of CS deposited Inconel 625 and Inconel 718 in $45^{\circ}$, longitudinal, i.e. spray direction $\left(0^{\circ}\right)$ and transverse, i.e. perpendicular to spray direction $\left(90^{\circ}\right)$ directions in as-sprayed condition and heat-treated condition, respectively. The results indicate that residual stress in as-sprayed Inconel 625 coatings is highly tensile in nature on the free surface of the coatings. The highest stress 
Fig. 2 SEM micrographs of the cross-sectional regions of CS deposited (a) Inconel 625 (assprayed), (b) Inconel 718, (c) Inconel 625 (heat treated), and (d) Inconel 718 (heat treated)
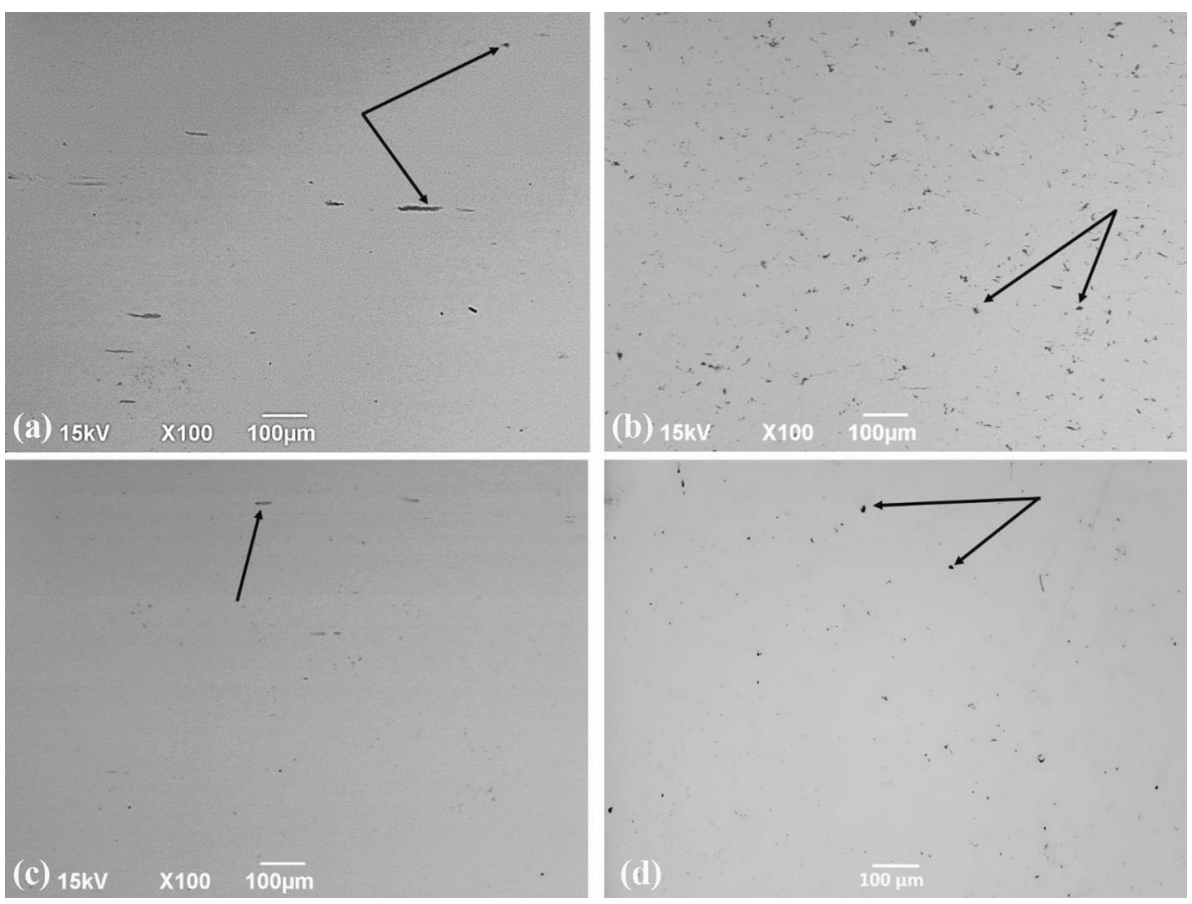

Table 4 Measured residual stress on the surface and inside of as-sprayed and heat treated cold sprayed samples using X-ray diffractometry

\begin{tabular}{|c|c|c|c|c|c|c|}
\hline \multirow[t]{3}{*}{ Sample Depth } & \multicolumn{6}{|c|}{ Residual Stress, MPa } \\
\hline & \multicolumn{3}{|c|}{ Before heat treatment } & \multicolumn{3}{|c|}{ After heat treatment } \\
\hline & Longitudinal $\left(0^{\circ}\right)$ & $45^{\circ}$ & $\overline{\text { Transverse }\left(90^{\circ}\right)}$ & Longitudinal $\left(0^{\circ}\right)$ & $45^{\circ}$ & Transverse $\left(90^{\circ}\right)$ \\
\hline Inconel 625 Surface & 598 & 752 & 974 & -56 & -45 & -36 \\
\hline Inconel $6251 \mathrm{~mm}$ & -195 & -159 & -229 & -54 & -32 & -46 \\
\hline Inconel 718 Surface & -160 & -65 & 27 & -161 & -193 & -158 \\
\hline Inconel $7181 \mathrm{~mm}$ & -199 & -133 & -225 & 35 & -20 & 7 \\
\hline
\end{tabular}

magnitude is in the transverse direction reaching 974MPa, gradually changing to compressive residual stress along the depth. The residual stress in compressive nature at the surface of Inconel 718 gradually increased along the depth of the coating sample. The highest compressive residual stress is on the surface along the longitudinal direction, reaching $160 \mathrm{MPa}$. Along the transverse direction, the residual stress behaves in tensile nature, reaching $27 \mathrm{MPa}$ at the surface of the sample and becoming compressive moving toward the coating core. It is important to consider residual stress formation in different directions beneath the surface of both coatings. The solid particles after impact resulted in higher stored compressive stress in transverse direction since it is perpendicular to spraying direction.

After the heat treatment at $800{ }^{\circ} \mathrm{C}$ for one hour, the residual stress in Inconel 625 was gradually relieved and became compressive in nature, as presented in Table 4. In the longitudinal direction, the compressive residual stress is the lowest, reaching $36 \mathrm{MPa}$. The reduction of porosity content after heat treatment may have contributed to the reduction of residual stress in CS deposited Inconel 625 . The reduction of porosities during heat treatment could induce tensile stress within the microstructure which worked in opposite direction of the existing residual stresses which were mainly compressive in nature. These two types of stresses with opposite signs could cancel each other and result in reduction of residual stress after heat treatment for Inconel 625. Similarly, heat treatment induces tensile stress due to the pore elimination within CS deposited Inconel 718 samples. The previously built residual stress during cold spraying tabulated in Table 4 can be accumulated with the one produced during heat treatment process because they both are compressive in nature. Therefore, the heat treatment resulted in increase in residual stress on the surface of Inconel 718 . 
The measured residual stresses before and after heat treatment for both materials in this study are better shown in Fig. 3. It is important to know that measurement of residual stress at the surface of any sample could significantly be affected by the surface preparation (grinding and polishing) before the x-ray diffraction experiment. Since the test specimens in this study were fabricated by similar technology having remarkably similar chemical compositions, formation of different types of residual stresses (tensile and compression) on the surfaces cannot be justified. External surface treatments such as grinding, polishing, grit blasting can alter the stress state on the surface of the samples whereas the stress state beneath the surface is not changed. To this end, the residual stress state beneath the free surface and closer to the core of coating has received more attention in this study which is approximately $1 \mathrm{~mm}$ beneath the surface.

The cold spraying process induces greater plastic deformation of the sprayed particles as the inter-particle bonding occurs after their impact and plastic deformation on the substrate. The results shown in Fig. 3 indicate that stress relief heat treatment has more significant effect on Inconel 718 than on Inconel 625.

Pore elimination results in formation of tensile stress in the materials. Since Inconel 718 contains more porosity as shown in Fig. 2, more tensile stress was formed during heat treatment. The decrease in residual stress of nickel-based superalloys has been previously reported in the literature; however, increasing heat treatment to $1100{ }^{\circ} \mathrm{C}$ has shown an inverse effect and resulted in an increase in residual stress (Ref 17). The measurement of residual stress at different heat treatment temperature is not in the scope of the current study. It is also important to take into consideration the amount of pore elimination and its effect on reduction of compressive residual stress at different orientations. Although it is not in the scope of this study, higher rate of compressive residual stress reduction can be clearly seen in transverse direction (perpendicular to spraying direction) for both CS deposited samples. It is important to provide a comparison between porosity level, residual stress and effect of heat treatment on both samples at subsurface regions. The porosity level in as-sprayed Inconel 625 is almost three times less than the one in assprayed Inconel 718 sample. After heat treatment, the porosities in Inconel 625 and Inconel 718 were approximately decreased by 42 and $48 \%$, respectively. The higher rate for pore elimination in Inconel 718 resulted in creation of higher tensile stress in this sample which consequently resulted in more annihilation of compressive residual stress formed during cold spraying process.

Vickers microhardness test was conducted on all coating samples to obtain better indication of their mechanical properties. Table 5 lists the measured hardness values before and after stress relaxation heat treatment for both materials. The as-sprayed Inconel 625 exhibits higher hardness compared to Inconel 718, and it is expected that the hardness would decrease after heat treatment for both materials. While due to the higher rate of pore elimination in Inconel 718, it is assumed that this sample may experience higher rate of decrease in hardness after heat treatment. However, the experimental results showed that the decrease in hardness was more significant in Inconel 625 sample. It indicates that softening of material after stress relaxation heat treatment in addition to pore elimination can depend on other parameters which can be studied separately in the future. The hardness results for the as-

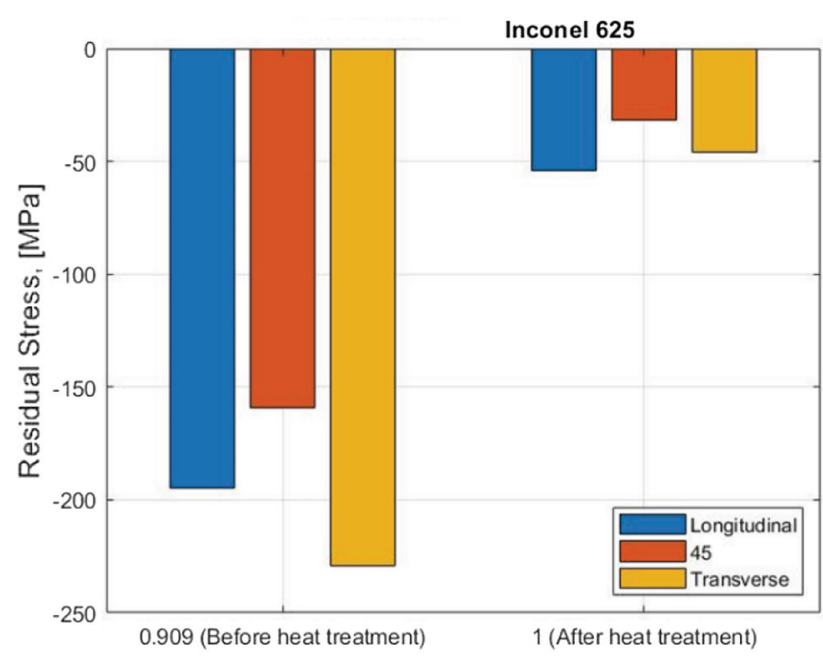

(a)

Depth, [mm]

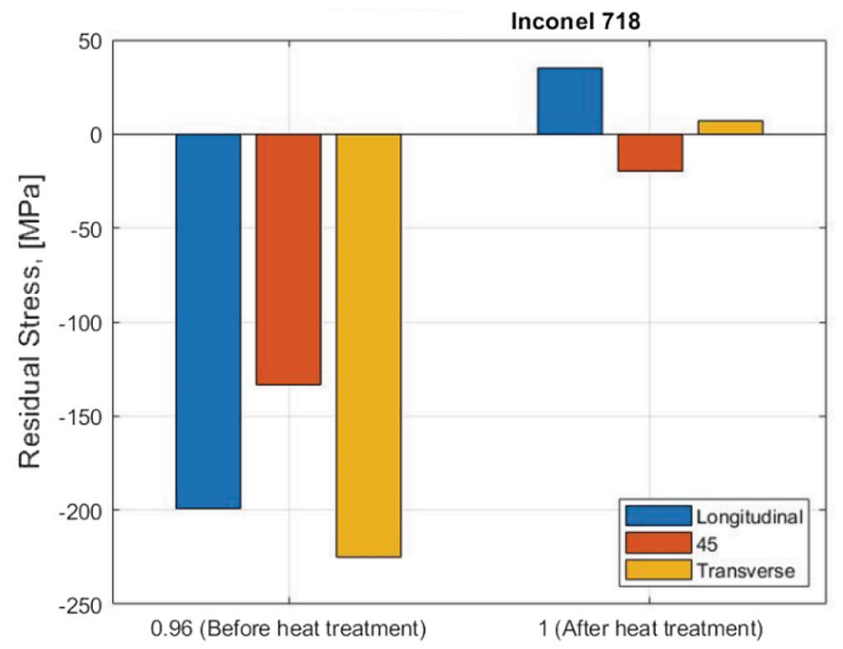

(b)

Depth, [mm]

Fig. 3 The measured residual stress from subsurface regions (inside the coating samples) before and after heat treatment (a) Inconel 625 , and (b) Inconel 718 in $45^{\circ}$, longitudinal and transverse directions (Color figure online) 
sprayed samples are in good agreement with the ones reported in the literature $(\operatorname{Ref} 23,29)$.

The indents and cracks produced around them during the micro indentation test were observed for both types of materials using a digital microscope. Several indentations were made on the cross-section of both types of materials at different loading conditions for visual study of the cracks. Figure 4 shows sample indents on as-sprayed Inconel 6256 (a) and Inconel 7186 (b) at 500 gf for 15 seconds, respectively. Cracks are visible on both samples around the diamond-shaped indents. The inset surface profile shows the depth of cracks measured from the bottom of the indent. Since the measurement was made in the upward direction from the very bottom of the indent, a lower value of depth with darker color indicates a deeper crack. The depth of cracks is about 8-10 $\mu \mathrm{m}$. Cracks are deep mainly around the corners of the indent in the Inconel 718 samples. The cracks in Inconel 625 were mainly along the sides of the indents. The accumulation of pre-existing residual stresses in the compressive nature (Fig. 3) with

Table 5 Measured Vickers hardness values of Inconel 625 and Inconel 718

\begin{tabular}{ccc}
\hline Element & As-Sprayed, HV & After heat treatment, HV \\
\hline Inconel 625 & $538.16 \pm 32.91$ & $406.54 \pm 38.91$ \\
Inconel 718 & $472.66 \pm 31.42$ & $414.76 \pm 33.42$ \\
\hline
\end{tabular}

further applied compressive stress during the indentation test led to the formation of cracks in both materials.

The same samples were investigated after stress relaxation heat treatment and indentation tests as well as shown in Fig 4(c) and (d). No visible cracks were seen in any of those heat-treated samples. The results are consistent with the x-ray diffraction residual stress measurements shown in Table 4 and Fig. 3 that indicate significant reduction of residual stress, resulting in no crack formation in both materials. Reduction of hardness and softening of the material can also contribute to elimination of cracks in heat-treated samples.

During microindentation test, a plastic zone is formed around the indention region. The residual stress develops due to the incompressibility of plastically deformed material which results in crack formation. Since the sign of residual stress formed during CS process is similar to the ones created during indentation test, it could increase the stress and result in larger cracks in the sample with larger amount of residual stress (e.g. Inconel 625) (Ref 30, 31).

It can also be concluded that the higher hardness in assprayed CS samples is due to the strain hardening of metallic particles during impact and flattening of powders. It is believed that the buildup of residual stress in the CS deposited coatings occurs at this stage of the process. On the other hand, defects such as dislocations could be produced (or increased) within the microstructure of the coatings after plastic deformation (Ref 32). However, stress relaxation heat treatment not only decreases the residual stress by elimination of porosity but also it can annihilate dislocations attributed to the energy provided by elevated
Fig. 4 Vickers Indentation on the cross-section of CS deposited (a) Inconel 625 (assprayed), (b) Inconel 718 (assprayed), (c) Inconel 625 (heat treated), (d) Inconel 718 (heattreated). Insets show the surface profile of indents and cracks.
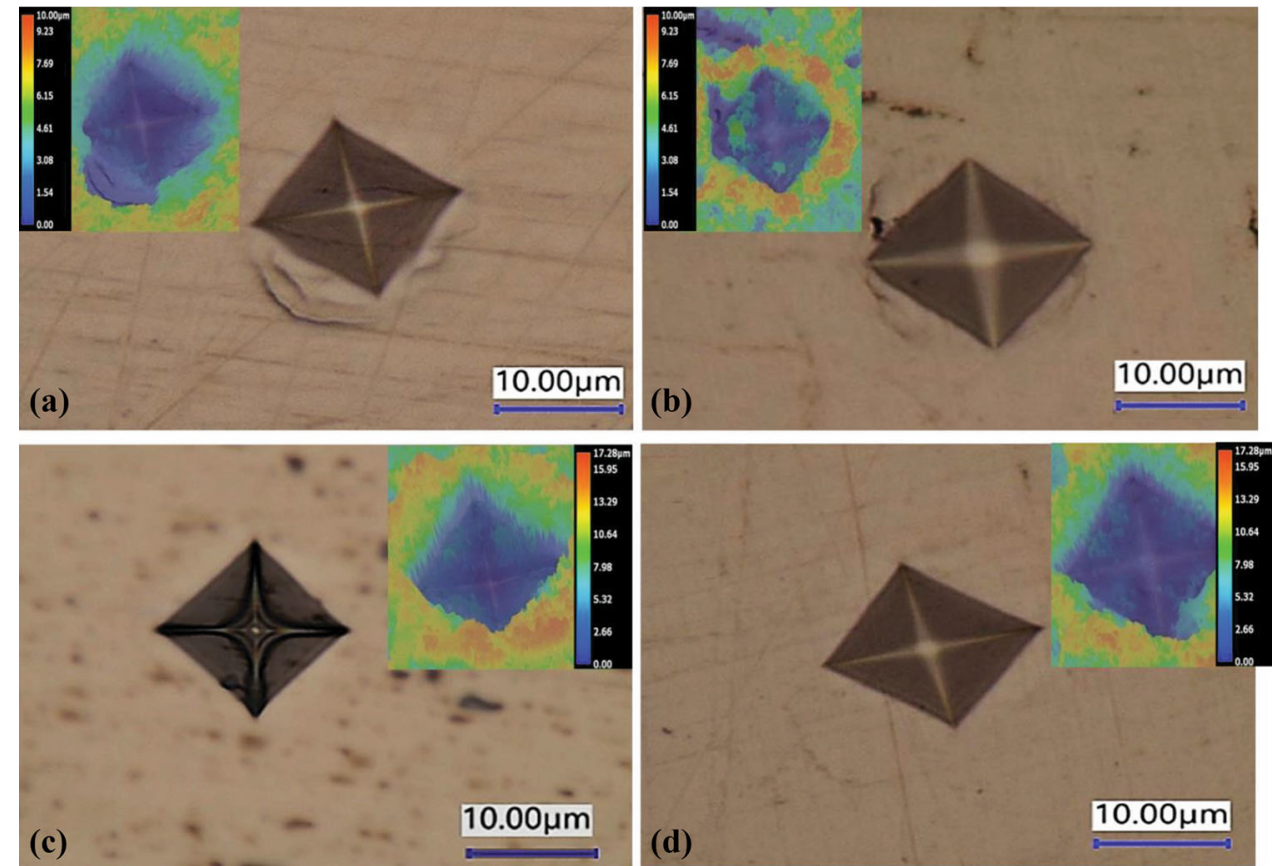
temperature. Consequently, hardness of the heat-treated samples decreases compared to the as-sprayed ones.

\section{Conclusion}

In this study, residual stress distributions in cold sprayed Inconel 625 and Inconel 718 were evaluated by the x-ray diffraction method. The effects of heat treatment on residual stress of both samples were also analyzed. Stress relief heat treatment was performed at $800^{\circ} \mathrm{C}$ for one hour on both materials. Residual stress in as-sprayed Inconel 625 was not uniform through the thickness. The residual stress was found to be highly tensile on the free surface while it became compressive towards the coating core. The residual stress distribution was different for CS deposited Inconel 718. The built-up residual stress in Inconel 718 was mostly compressive in nature in both surface and subsurface regions. Since residual stress of the surface could be influenced by preparation of the samples, only residual stress in the subsurface regions was studied here. Regardless of the material, the residual stress formed inside of both cold sprayed samples had a compressive nature and it was higher in Inconel 718. The porosity level was higher in as-sprayed Inconel 718 sample which can be one of the reasons for its lower hardness compared to Inconel 625 coating. The heat treatment-induced tensile stress due to elimination of porosities within the microstructure of both coating samples. Since it was in opposite sign as the compressive residual stress in Inconel 625, it could cancel out the previously built residual stress. Since Inconel 718 contained more porosity, it is expected that higher tensile stress formed in this sample due to the elimination of pores during heat-treatment process. While heat treated Inconel 625 coating still exhibits higher hardness compared to the Inconel 718 one but the rate of decrease in hardness was higher in Inconel 625 after the stress relaxation process. This study also tries to link microstructural features to the mechanical behaviors of the studied samples. Microstructural observations on both coating samples before and after heat treatment showed that both as-sprayed samples exhibit some cracks due to the intentionally made indentations on their cross-sections. However, the heat-treated samples do not show any visible cracks which could attribute to the softening and reduction of residual stress within the microstructure of both CS deposited samples.

Acknowledgments The authors would like to thank NDSU Electron Microscopy Center, for microstructural characterization using SEM. This study was partially funded by ND EPSCoR-Seed Award to Collect preliminary data.

\section{References}

1. W. Ma, Y. Xie, C. Chen, H. Fukanuma, J. Wang, Z. Ren and R. Huang, Microstructural and Mechanical Properties of High-Performance Inconel 718 Alloy by Cold Spraying, J. Alloys Compd., 2019, 792, p 456-467.

2. X. Zhao, J. Chen, X. Lin and W. Huang, Study on Microstructure and Mechanical Properties of Laser Rapid Forming Inconel 718, Mater. Sci. Eng. A, 2008, 478(1), p 119-124.

3. J.R. Davis, ASM Specialty Handbook: Nickel, Cobalt and Their Alloys, ASM International, Materials Park, OH, 2000.

4. INCONEL alloy 625, Special Metals Corporation, 2013, No. 2, p. $1-18$

5. S.S. Babu and R. Goodridge, Additive Manufacturing, Mater. Sci. Technol., 2015, 31(8), p 881-883.

6. T. DebRoy, H.L. Wei, J.S. Zuback, T. Mukherjee, J.W. Elmer, J.O. Milewski, A.M. Beese, A. Wilson-Heid, A. De and W. Zhang, Additive Manufacturing of Metallic Components-Process, Structure and Properties, Prog. Mater. Sci., 2018, 92, p 112-224.

7. D.D. Gu, W. Meiners, K. Wissenbach and R. Poprawe, Laser Additive Manufacturing of Metallic Components: Materials, Processes and Mechanisms, Int. Mater. Rev., 2012, 57(3), p 133164.

8. S. Marx, A. Paul, A. Kohler and G. Huttl, Cold Spraying: Innovative Layers for New Applications, J. Therm. Spray Technol., 2006, 15(2), p 177-183.

9. A. Moridi, S.M. Hassani-Gangaraj, M. Guagliano and M. Dao, Cold Spray Coating: Review of Material Systems and Future Perspectives, Surf. Eng., 2014, 30(6), p 369-395.

10. H. Assadi, H. Kreye, F. Gartner and T. Glassen, Cold Spraying-A materials perspective, Acta Mater., 2016, 166, p 382-407.

11. D. Boruah, X. Zhang and M. Dore, Theoretical Prediction of Residual Stresses Induced by Cold Spray with Experimental Validation, Multidiscip. Modell. Mater. Struct., 2019, 15(3), p 599-616.

12. T. Berruti, M. Lavella and M.M. Gola, Residual Stresses on Inconel 718 Turbine Shaft Samples after Turning, Mach. Sci. Technol., 2009, 13(4), p 543-560.

13. Z. Chen, R. Lin Peng, P. Avdovic, J. Moverare, F. Karlsson, J.M. Zhou and S. Johansson, Analysis on Thermal Effect on Residual Stresses of Broached Inconel 718, Adv. Mater. Res., 2014, 996, p 574-579.

14. L. Wu and C. Jiang, Effect of Thermal Relaxation on Residual Stress and Microstructure in the near-surface Layers of Dual Shot Peened Inconel 625, Adv. Mech. Eng., 2018, 10(10), p 1-6.

15. C. Lyphout, P. Nylen, A. Manescu and T. Pirling, Residual Stresses Distribution Through Thick HVOF Sprayed Inconel 718 Coatings, J. Therm. Spray Technol., 2008, 17(5), p 915-923.

16. X. Wang and K. Chou, The Effects of Stress Relieving Heat Treatment on the Microstructure and Residual Stress of Inconel 718 Fabricated by Laser Metal Powder Bed Fusion Additive Manufacturing Process, J. Manuf. Process., 2019, 48, p 154-163.

17. S.Y. Kim, V. Luzin, M.L. Sesso, J. Thornton and S. Gulizia, The Effect of Low Temperature Range Heat Treatment on the Residual Stress of Cold Gas Dynamic Sprayed Inconel 718 Coatings via Neutron Diffraction, J. Therm. Spray Technol., 2020, 29(6), p 1477-1497.

18. R. Singh, S. Schruefer, S. Wilson, J. Gibmeier and R. Vassen, Influence of Coating Thickness on Residual Stress and AdhesionStrength of Cold-Sprayed Inconel 718 Coatings, Surf. Coat. Technol., 2018, 350, p 65-73.

19. Z. Arabgol, H. Assadi, T. Schmidt, F. Gartner and T. Glassen, Analysis of Thermal History and Residual Stress in Cold-Sprayed Coatings, J. Therm. Spray Technol., 2014, 23(1), p 84-90. 
20. E. Lin, I. Nault, O.C. Ozdemir, V.K. Champagne, A. Nardi and S. Muftu, Thermo-Mechanical Deformation History and the Residual Stress Distribution in Cold Spray, J. Therm. Spray Technol., 2020, 29(6), p 1424-1436.

21. F. Azarmi and I. Sevostianov, Evaluation of the Residual Stresses in Metallic Materials Produced by Additive Manufacturing Technology, Curr. Opin. Chem. Eng., 2020, 28, p 21-27.

22. E.A. Brandes and G.B. Brook, Smithells Metals Reference Book, 7th ed. Butterworth-Heinemann Ltd., Oxford, 1992.

23. F. Azarmi and I. Sevostianov, Comparative Micromechanical Analysis of Alloy 625 Coatings Deposited by Air Plasma Spraying, Wire Arc Spraying, and Cold Spraying Technologies, Mech. Mater., 2020, 144, p 103345.

24. P.S. Prevey, X-ray Diffraction Residual Stress Techniques, ASM International, Ohio, 1986.

25. ASTM E407-07, Standard Practice for Microetching Metals and Alloys. PA: ASTM International, West Conshohocken, 2015.

26. ASTM, E92-17, Standard Test Methods for Vickers Hardness and Knoop Hardness of Metallic Material, 2017

27. Heat Treating, ASM Handbook, 1991, 4, ASM International
28. H. Hamatani, Y. Ichiyama and J. Kobayashi, Mechanical and Thermal Properties of HVOF Sprayed Ni Based Alloys with Carbide, Sci. Technol. Adv. Mater., 2002, 3(4), p 319-326.

29. L.I. Pérez-Andrade, F. Gärtner, M. Villa-Vidaller, T. Klassen, J. Muñoz-Saldaña and J.M. Alvarado-Orozco, Optimization of Inconel 718 Thick Deposits by Cold Spray Processing and Annealing, Surf. Coat. Technol., 2019, 378, p 124997.

30. K.L. Johnson, The Correlation of Indentation Experiments, $J$. Mech. Phys. Solids, 1970, 18, p 115-126.

31. X. Chen, J. Yan and A.M. Karlsson, On the Determination of Residual Stress and Mechanical Properties by Indentation, Mater. Sci. Eng., A, 2006, 416(1), p 139-149.

32. J. Callister, Materials Science and Engineering, $10^{\text {th }} \mathrm{Ed}$ (E-book), ISBN: 978-1-119-40549-8., Wiley \& Sons, Inc., 2018

Publisher's Note Springer Nature remains neutral with regard to jurisdictional claims in published maps and institutional affiliations. 